\title{
Sistem Informasi Geografis Lokasi Kualitas Air Pada PDAM Patriot Bekasi
}

\author{
Yoga Saputra ${ }^{1}$, Abrar Hiswara ${ }^{1}$, Rafika Sari ${ }^{1,}$ \\ *Korespondensi: rafika.sari@dsn.ubharajaya.ac.id
}

\begin{abstract}
1 Program Studi Informatika; Universitas Bhayangkara Jakarta Raya; Jl. Raya Perjuangan, Margamulya, Bekasi; telp.(021) 7231948; gyo.yoga@gmail.com, abrar.hiswara@dsn.ubharajaya.ac.id,rafika.sari@dsn.ub harajaya.ac.id
\end{abstract}

Submitted: 11 Oktober 2020

Revised: 1 November 2020

Accepted: 15 November 2020

Published: 30 November 2020

\section{Abstract}

The digital information technology as humans today is a very important thing. Clean water is a basic human need that is met, so the need for a web-based Geographic Information System (GIS) as a digital information media about service requirements, sub-district boundaries, residential buildings, existing pipelines and locations of air quality specifically PDAM Tirta Patriot Bekasi city. The system development method used is the waterfall model. Data collection is a method of interview, observation, study of literature. The system design uses UML, the system is built using the PHP programming language, Javascript, with a MySQL database, on system testing with Blackbox Testing. Converting vector data into GeoJSON on the Quantum GIS application. It is hoped that this can help the PDAM Tirta Patriot of the City of Bekasi in providing information requested services, sub-district boundaries, housing buildings, pipelines in the distribution of clean air to the community, then provide information to customers of the Tirta Patriot City of Bekasi in viewing the point location of water quality in 3 housing complexes with the highest number of customers of PDAM Tirta Patriot of Bekasi City, Results that are in accordance with the service location and district area of the City of Bekasi, residential buildings, existing pipelines, and the location of the customer complaint water point from GIS information based on customer satisfaction survey data.

Keywords: Geographic Information System, PDAM, Waterfall, Google Maps, OpenStreetMap.

\section{Abstrak}

Kebutuhan akan teknologi informasi digital sebagai manusia zaman sekarang merupakan hal pokok yang sangat diperlukan. Air bersih merupakan suatu kebutuhan yang mendasar manusia sebagai kelangsungan hidupnya, maka perlu adanya Sistem Informasi Geografis (SIG) berbasis web sebagai media informasi peta digital mengenai cakupan layanan, batas wilayah kecamatan, bangunan perumahan, jaringan pipa existing dan lokasi kualitas air khususnya PDAM Tirta Patriot Kota Bekasi. Metode pengembangan sistem yang digunakan model waterfall. Pengumpulan datanya yaitu metode wawancara, observasi, studi pustaka. Perancangan sistem menggunakan UML, sistem ini dibangun menggunakan bahasa pemrograman PHP, Javascript, dengan basis data MySQL, pada pengujian sistem dengan Blackbox Testing. Konversasi data vektor ke dalam GeoJSON pada aplikasi Quantum GIS. Yang diharapkan ini bisa membantu PDAM Tirta Patriot Kota Bekasi dalam menyajikan informasi cakupan layanan, batas wilayah kecamatan, bangunan perumahan, jaringan pipa existing dalam distribusi air bersih kepada masyarakat, kemudian memberikan informasi pada pelanggan PDAM Tirta Patriot Kota Bekasi dalam melihat titik lokasi kualitas air di 3 perumahan dengan jumlah pelanggan terbanyak PDAM Tirta Patriot Kota 
Bekasi, Hasil yang ditampilkan berupa peta cakupan layanan dan wilayah kecamatan Kota Bekasi, bangunan perumahan, jaringan pipa existing, dan lokasi titik air keluhan pelanggan dari informasi GIS berdasarkan data survei kepuasan pelanggan.
Kata kunci: Geographic Information System, PDAM, Waterfall, Google Maps, OpenStreetMap.

\section{Pendahuluan}

Kebutuhan akan teknologi informasi merupakan hal pokok yang sangat diperlukan. Kebutuhan akan mendapatkan suatu informasi yang cepat, tepat dan efisiensi tersebut maka diperlukannya suatu sistem yang nantinya dapat membantu mempermudah manusia dalam pekerjaannya.

Air bersih merupakan suatu kebutuhan yang mendasar manusia bagi kelangsungan hidupnya. Meningkatnya permintaan air bersih berasal dari penduduk dengan ekonomi yang semakin bertumbuh. Hal ini berakibat terbatasnya distribusi air bersih yang layak untuk dikonsumsi. Hal yang menjadi penyebab terbatasnya air bersih yang layak untuk dikonsumsi apabila pada sumber air baku terdampak limbah, sehingga produk air yang dihasilkan tidak dapat memenuhi standar dari pelayanan kemudian akan mengalami penurunan volume air.

Melihat dari upaya meningkatkan pelayanan tersebut, maka perlu adanya Sistem Informasi Geografis (SIG) berbasis web sebagai media informasi peta digital mengenai cakupan layanan dan batas wilayah kecamatan Kota Bekasi, bangunan perumahan, jaringan pipa existing dan lokasi kualitas air. Yang diharapkan SIG ini bisa membantu untuk mengoptimalkan pada pelayanan distribusi air bersih kepada masyarakat. SIG bisa menjadi alat yang penting dalam hal menyajikan data dan peta dari sumber-sumber yang langsung berhubungan mengenai kepentingan masyarakat. Dengan begitu, akan mempunyai akses cepat, akurat agar informasi geografis dapat membantu mempercepat peningkatan layanan bagi masyarakat.

Hal ini tentu dapat mempermudah pelanggan mendapat informasi kualitas air yang telah dikembangkan oleh PDAM Tirta Patriot. Bagi PDAM Tirta Patriot dapat dijadikan modal dalam mempromosikan dan lebih mengembangkan layanan kepada pelanggan terhadap kebutuhan air bersih PDAM Tirta Patriot.

Dalam beberapa tahun terakhir, dengan kemajuan dalam perkembangan SIG, semakin banyak penyelenggara SPAM yang dapat membeli software SIG dengan harga terjangkau. Data informasi SIG dapat menjadi landasan pemetaan fasilitas penyediaan air minum, seperti data pemetaan saluran pipa dapat menunjang operasional penyediaan air minum.

Pada tahun 2012 merupakan awal dimulainya SIG di PDAM Tirta Patriot Kota Bekasi, dengan menggunakan aplikasi SIG yang bernama MapInfo, lalu Oktober 2016 kegiatan SIG ini berjalan kembali dalam pengaplikasiannya SIG menggunakan perangkat lunak Quantum GIS (QGIS) merupakan salah satu perangkat lunak sistem informasi geografis yang terkenal karena dibangun dengan komunitas qgis.org. Kemampuan QGIS dapat bersaing dengan software SIG berbayar lain seperti produk dari ESRI. Sehingga dengan adanya aplikasi sistem informasi 
geografis berbasis desktop ini dapat menunjang kegiatan operasional PDAM, serta berkaitan juga dengan kinerja perusahaan.

Oleh karena itu, penyempurnaan pada data SIG sangat penting dalam kelanjutan pembangunan perkotaan. Pemetaan informasi dapat dilakukan dengan lebih mudah jika integrasi informasi wilayah pelanggan dan properti aset perusahaan ke database sudah dilakukan. Penyelenggara SPAM tidak perlu memprioritaskan data dengan akurasi tinggi karena SIG dapat dihasilkan dari pengolahan data seperti penyedia peta gratis OSM.

Maka adanya SIG berbasis web ini dapat dikategorikan yang akan ditandai berupa (point) dengan menitikkan lokasi wilayah rumah pelanggan yang dampaknya seperti hijau (air bersih/lancar), kuning (air keruh/kotor), merah (air mati/tidak keluar), dan lingkupnya pada 3 perumahan dengan jumlah pelanggan terbanyak pada PDAM Tirta Patriot. Sistem Informasi Geografis Lokasi Kualitas Air PDAM Patriot Bekasi ini membantu pelanggan dalam mendapat informasi jangkauan cakupan dan titik lokasi kualitas air dari layanan PDAM Tirta Patriot, sedangkan untuk PDAM Tirta Patriot dapat mengembangkan kembali citra layanan yang selama ini sering menjadi keluhan dari para masyarakat khususnya pelanggan setia PDAM Tirta Patriot.

Berdasarkan penelitian terdahulu yang dilakukan oleh (Maudi et al., 2014) dengan judul Desain Aplikasi Sistem Informasi Pelanggan PDAM BERBASIS WEBGIS (STUDI KASUS : KOTA DEMAK) Penelitian tersebut mengambil studi kasus di Kota Demak. Dari penelitian yang dilakukan menghasilkan sebuah sistem informasi geografis pemetaan pelanggan PDAM berbasis webgis yang mempunyai fungsi sebagai penyambung antara pelanggan PDAM dan instansi PDAM Demak secara user friendly.

Pada penelitian yang dilakukan (Susila et al., 2016) dengan judul Sistem Informasi Geografis Pemetaan Jaringan Pipa PDAM Tirta Mangutama fungsinya adalah pendistribusian air bersih kepada masyarakat yaitu membantu mendapatkan informasi jaringan pipa dengan mudah dan cepat jaringan pipa, informasi yang ditampilkan disistem data pemetaan jaringan pipa primer, pipa sekunder, reservoir, sumber air dan aksesoris.

Pada penelitian yang dilakukan (Karimah, 2012) dengan judul Sistem Informasi Geografis Pemetaan Sumber Air dan Reservoir Kabupaten Sleman dapat disimpulkan yaitu sistem informasi yang di rancang dapat membantu dalam mendata sumber air, reservoir dan aliran pipa yang ada di wilayah Kabupaten Sleman fungsinya dapat membantu PDAM pada bagian produksi dan distribusi dalam mengelola data produksi dan distribusi secara lebih terorganisir dan terstruktur.

\section{Metode Penelitian}

\subsection{Perancangan Sistem}

Dalam analisa sistem usulan dapat digunakan sebagai pembanding dengan sistem berjalan yang ada, maka dapat diketahui apakah sudah tepat tingkat sistem yang dilakukan pada sistem yang baru dengan sistem berjalan. Yang mana agar sistem baru tersebut mampu 
mengisi kekurangan yang ada pada sistem berjalan. Oleh sebab itu sistem baru yang akan diusulkan yaitu membuat Sistem Informasi Geografis Lokasi Kualitas Air PDAM Patriot Bekasi. Diharapkan dapat lebih efisien dalam penyampaian informasi pada pelanggan dan menunjang operasional penyediaan air minum khususnya di Kota Bekasi

\subsection{Diagram Use Case}

Use case adalah diagram yang digunakan untuk menggambarkan kebutuhan pengguna pada perilaku sistem. Use case terdiri dari actor, use case serta hubungannya. Use case diagram dapat dilihat pada gambar 1 .

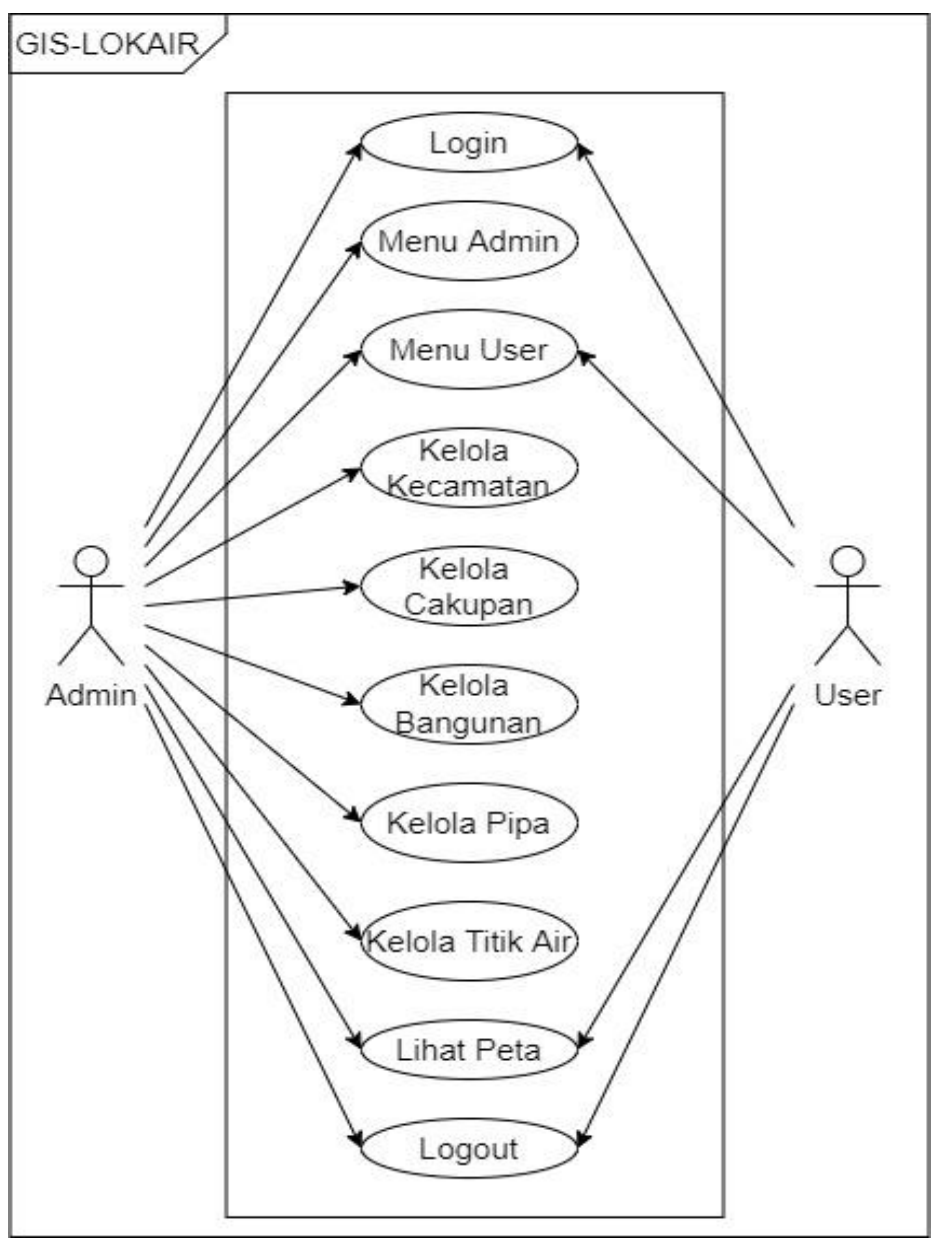

Sumber: Hasil Penelitian (2020)

Gambar 1. Use case Diagram Sistem Usulan

Definisi Use case terdapat deskripsi dari masing - masing use case yang berada pada Sistem Informasi Geografis Lokasi Kualitas Air PDAM Patriot Bekasi, seperti berikut: 
Tabel 1. Definisi Use case

\begin{tabular}{|c|c|c|}
\hline Id & Use case & Deskripsi \\
\hline UC-01 & Login & $\begin{array}{l}\text { Menggambarkan pengguna admin dan user dalam } \\
\text { melakukan login sesuai dengan hak akses masing - } \\
\text { masing }\end{array}$ \\
\hline UC-02 & Admin & $\begin{array}{l}\text { Menggambarkan pengguna admin dapat menambah, } \\
\text { melihat dan menghapus data user }\end{array}$ \\
\hline UC-03 & User & $\begin{array}{l}\text { Menggambarkan pengguna admin dan user dalam } \\
\text { melihat profil, mengubah profil user dan mengubah } \\
\text { password user }\end{array}$ \\
\hline UC-04 & Kelola Kecamatan & $\begin{array}{l}\text { Menggambarkan pengguna admin dalam mengelola } \\
\text { kecamatan data batas administrasi Kota Bekasi, yaitu } \\
\text { menambah, mengubah dan menghapus }\end{array}$ \\
\hline UC-05 & Kelola Cakupan & $\begin{array}{l}\text { Menggambarkan pengguna admin dalam mengelola } \\
\text { data cakupan SPAM PDAM Patriot Kota Bekasi, yaitu } \\
\text { menambah, mengubah dan menghapus }\end{array}$ \\
\hline UC-06 & Kelola Bangunan & $\begin{array}{l}\text { Menggambarkan pengguna admin dalam mengelola } \\
\text { data bangunan perumahan seperti menambah, } \\
\text { mengubah dan menghapus }\end{array}$ \\
\hline UC-07 & Kelola Pipa & $\begin{array}{l}\text { Menggambarkan pengguna admin dalam mengelola } \\
\text { data jaringan pipa seperti menambah, mengubah dan } \\
\text { menghapus }\end{array}$ \\
\hline UC-08 & Kelola Titik Air & $\begin{array}{l}\text { Menggambarkan pengguna admin dalam mengelola } \\
\text { data lokasi titik air seperti menambah, mengubah dan } \\
\text { menghapus }\end{array}$ \\
\hline UC-09 & Lihat Peta & $\begin{array}{l}\text { Menggambarkan pengguna dapat melihat pemetaan } \\
\text { yang tersedia beserta informasi nya dan melakukan } \\
\text { pencarian titik lokasi, memilih base map atau } \\
\text { menggunakan panel layer }\end{array}$ \\
\hline UC-10 & Logout & $\begin{array}{l}\text { Menggambarkan pengguna dalam melakukan logout } \\
\text { untuk keluar dari sistem }\end{array}$ \\
\hline
\end{tabular}

Sumber: Hasil Penelitian (2020)

\subsection{Diagram Activity}

Activity diagram adalah diagram yang digunakan untuk menggambarkan aktivitas utama dan hubungan di antara aktivitas di dalam proses sistem ini. Di bawah berikut akan di jelaskan mengenai activity diagram Sistem Informasi Geografis Lokasi Kualitas Air PDAM Patriot Bekasi. Tabel 2 menunjukkan diagram activity pada penelitian ini. 
Tabel 2. Diagram Activity

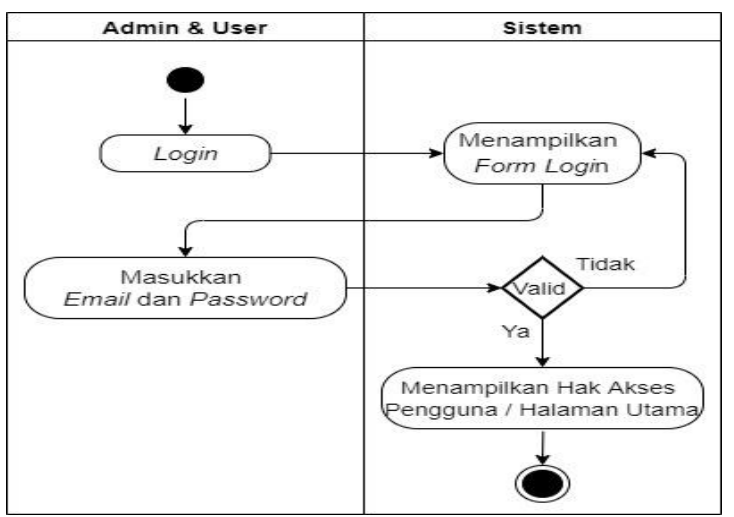

Activity Diagram Login

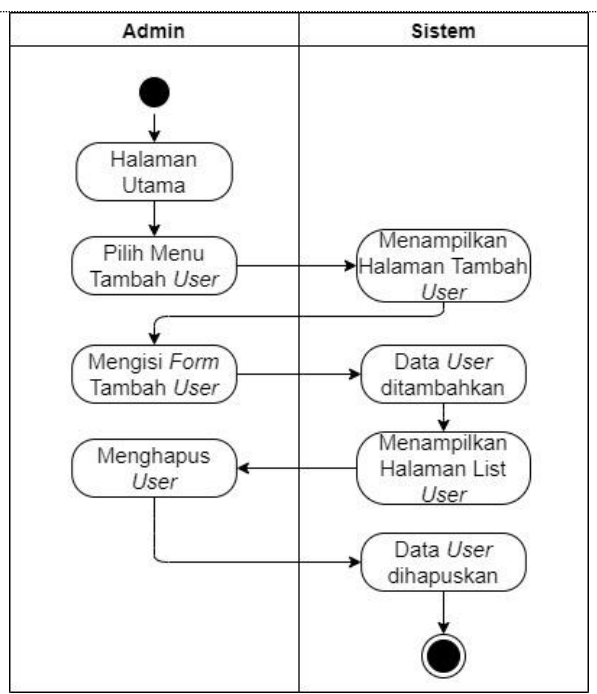

Activity Diagram Admin

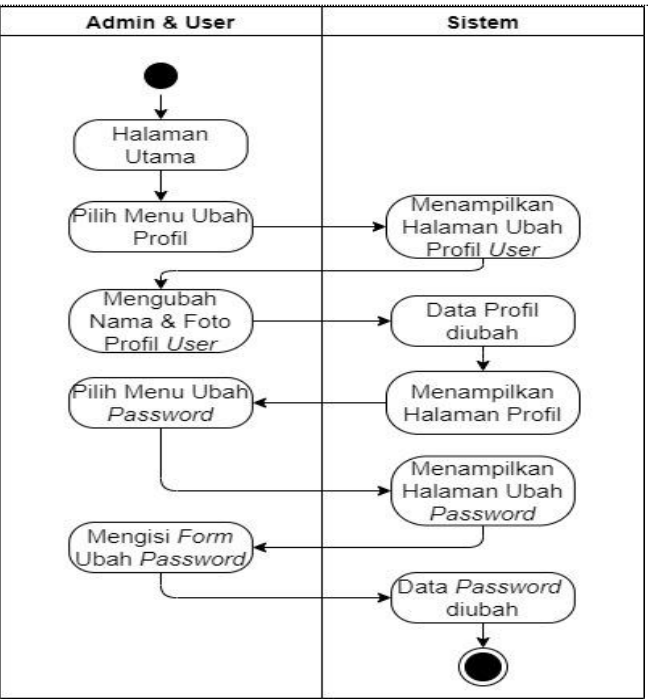

Activity Diagram User

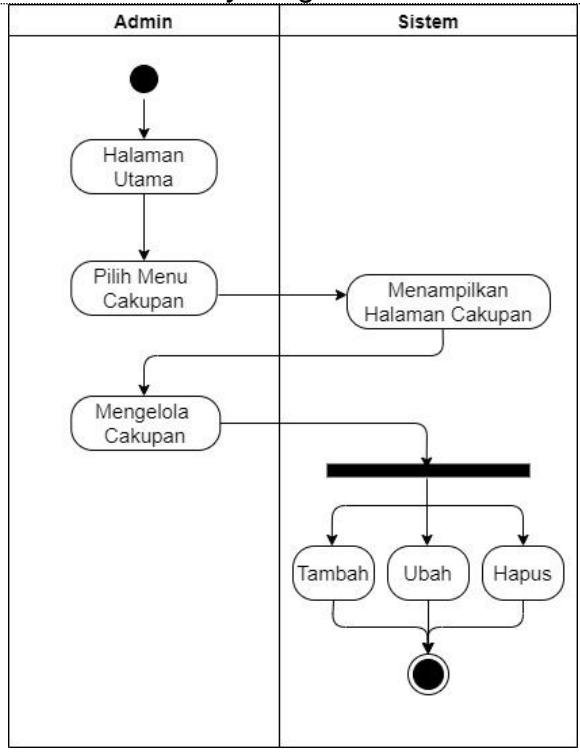

Activity Diagram Kelola Cakupan

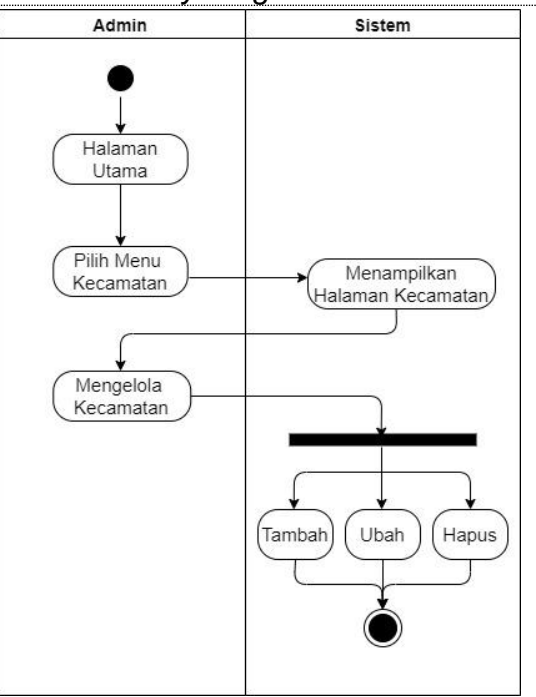

Activity Diagram Kelola Kecamatan

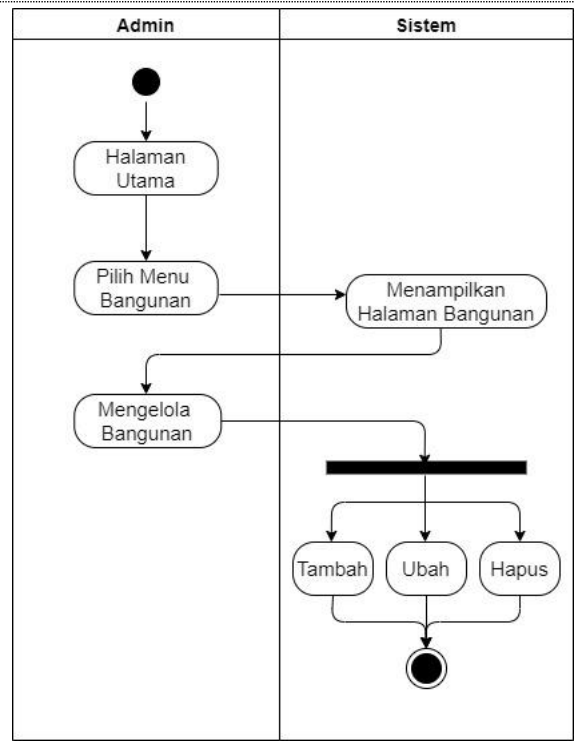

Activity Diagram Kelola Bangunan 


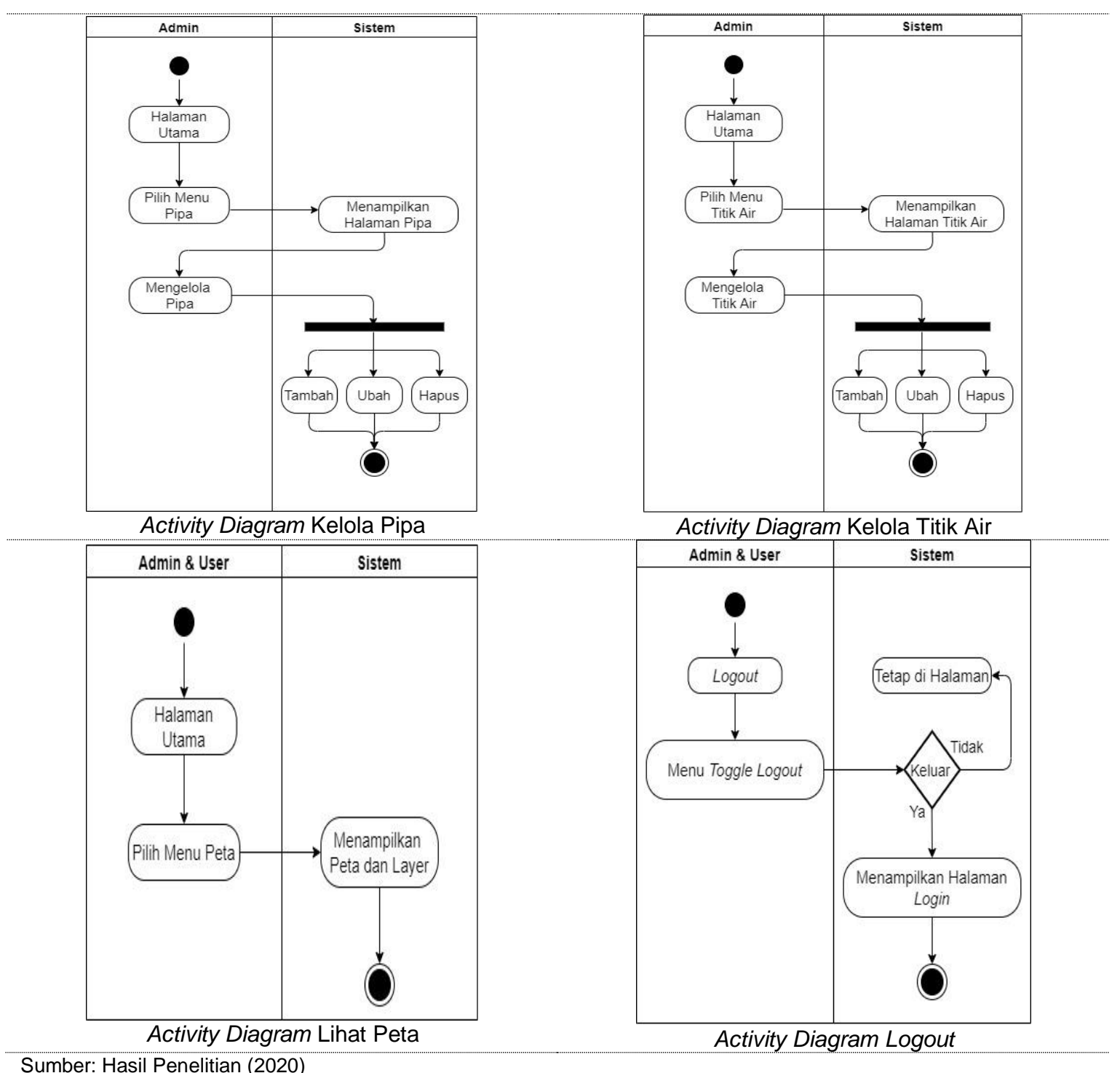
Sumber: Hasil Penelitian (2020)

\section{Hasil dan Pembahasan}

\subsection{Implementasi User Interface}

Dalam analisa sistem usulan dapat digunakan sebagai pembanding dengan sistem berjalan yang ada, maka dapat diketahui apakah sudah tepat tingkat sistem yang dilakukan pada sistem yang baru dengan sistem berjalan. Yang mana agar sistem baru tersebut mampu mengisi kekurangan yang ada pada sistem berjalan. Oleh sebab itu sistem baru yang akan diusulkan yaitu membuat Sistem Informasi Geografis Lokasi Kualitas Air PDAM Patriot Bekasi. Diharapkan dapat lebih efisien dalam penyampaian informasi pada pelanggan dan menunjang operasional penyediaan air minum khususnya di Kota Bekasi.

Implementasi User Interface yaitu menjelaskan mengenai paparan setiap halaman pada sistem aplikasi GIS-LOKAIR ini, seperti disajikan pada tabel 3. 
Tabel 3. Tampilan User Interface
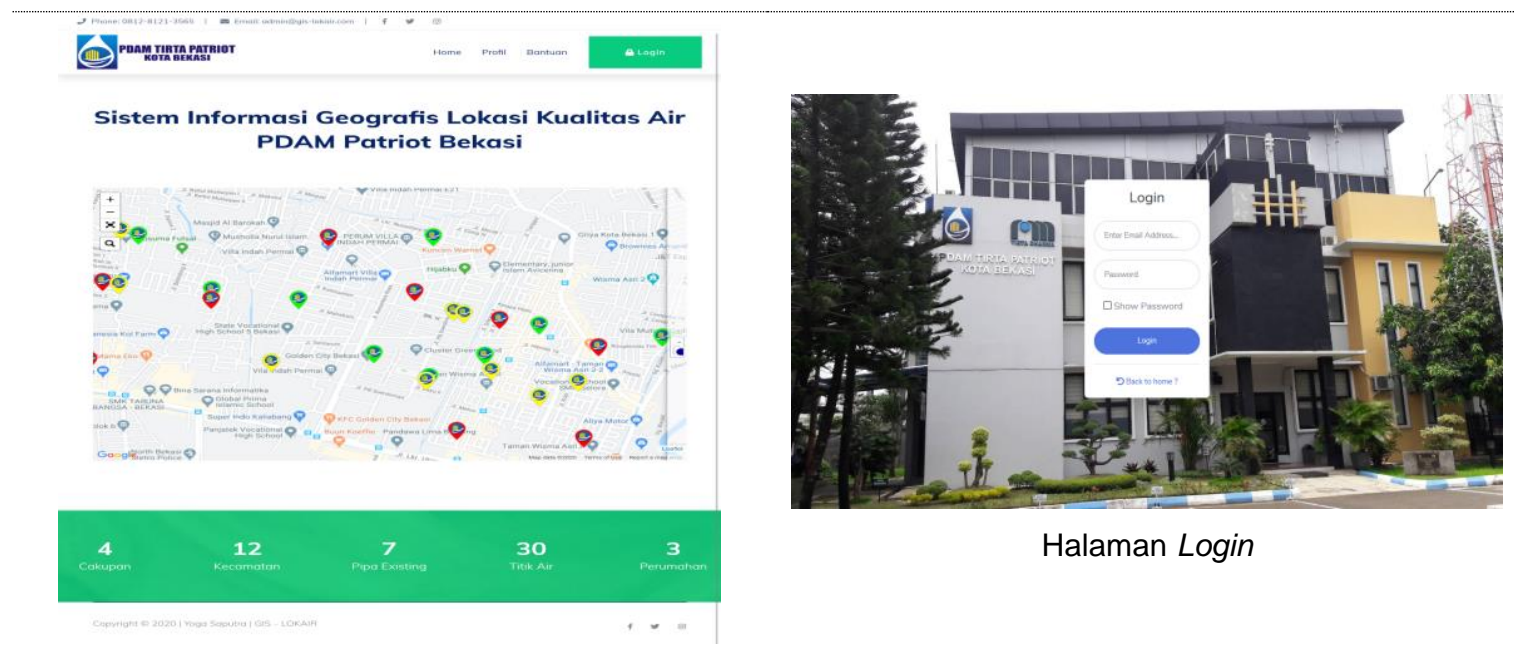

Halaman Login

Halaman Home
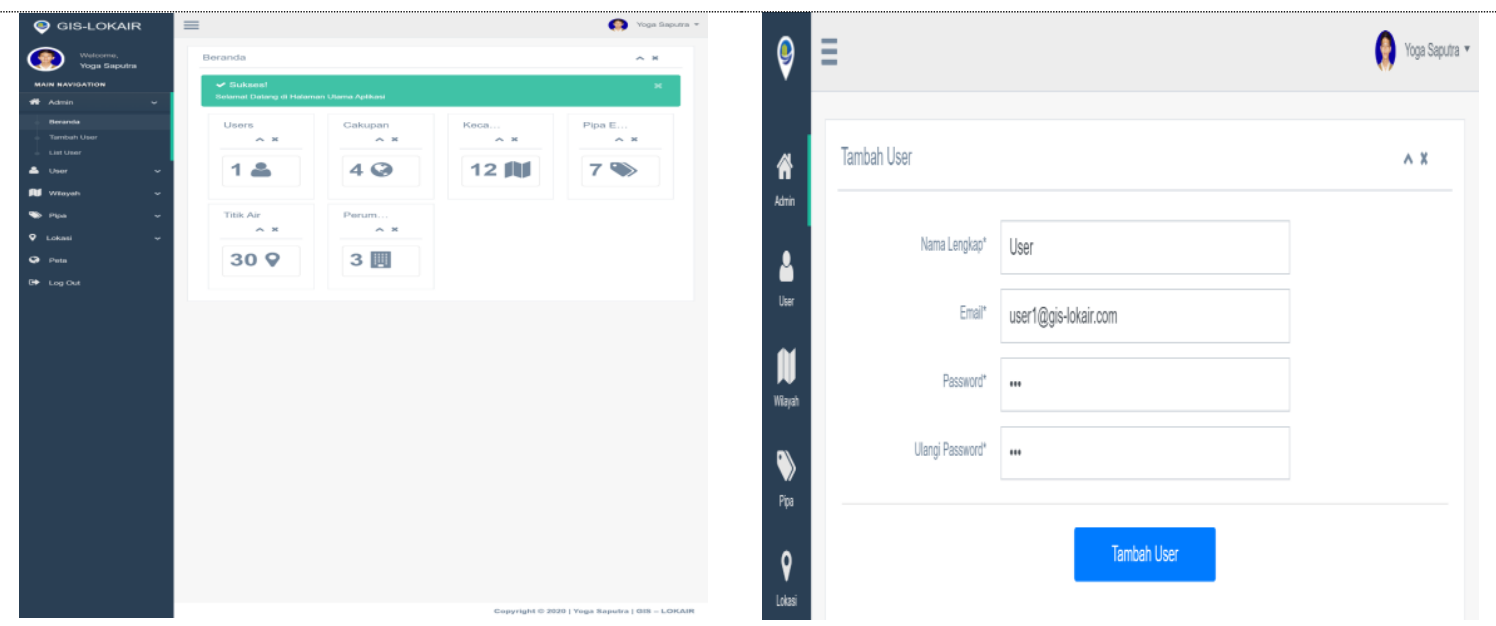

Halaman Beranda

Halaman Tambah User

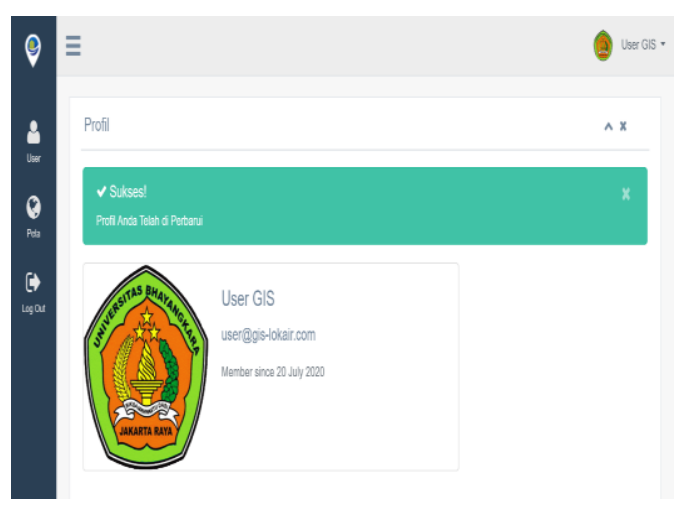

Halaman Profil Info Sukses Ubah Profil User

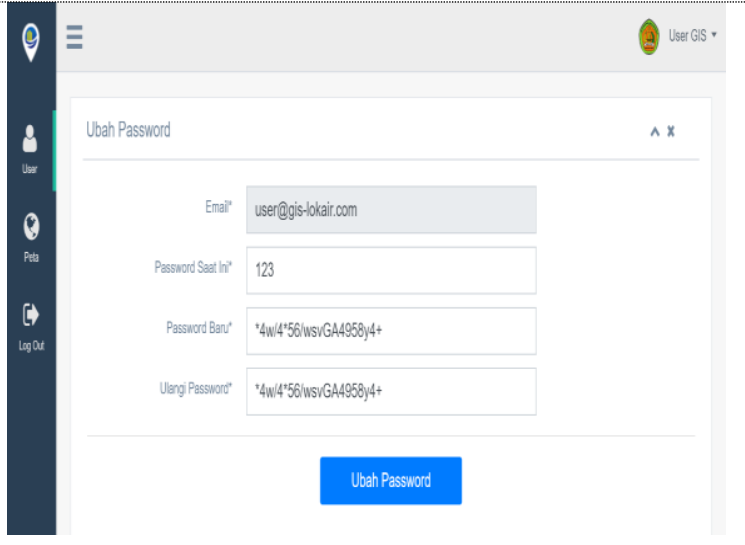

Halaman Ubah Password User 


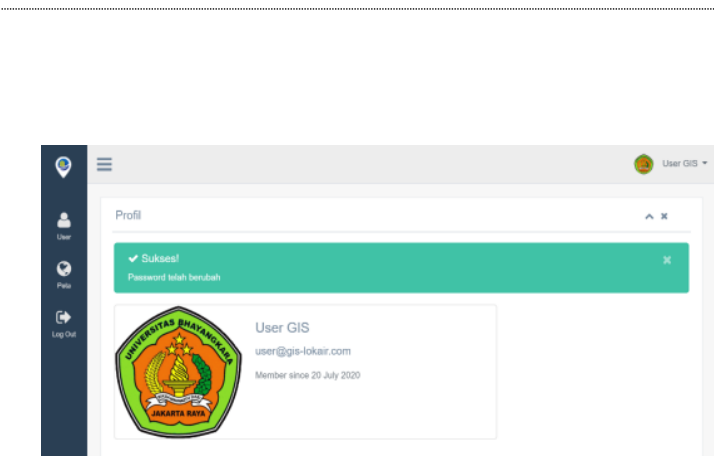

Halaman Profil Info Sukses Ubah Password User

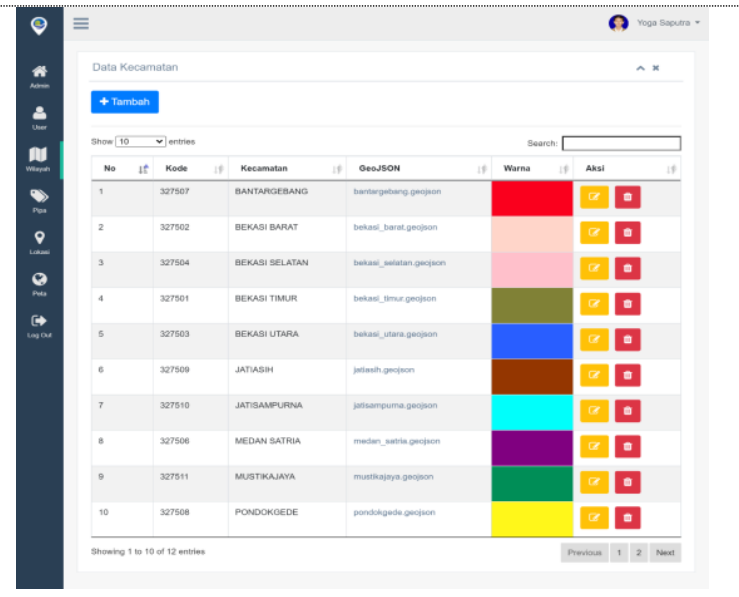

Halaman Kecamatan

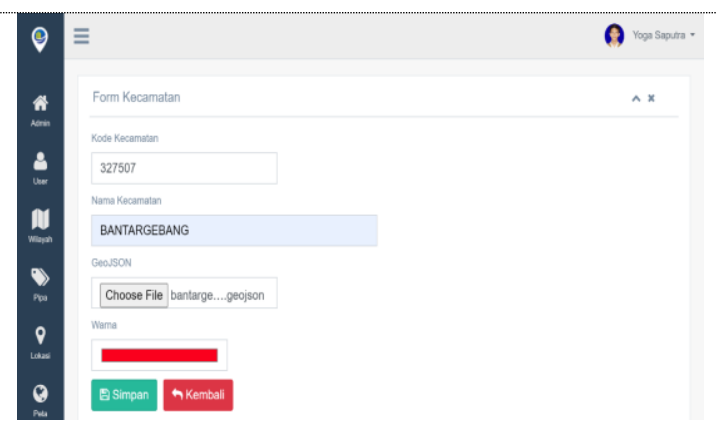

Halaman Tambah dan Ubah Kecamatan
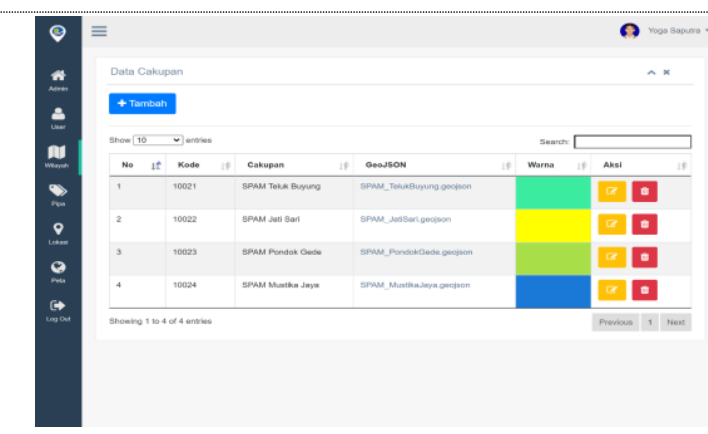

Halaman Cakupan

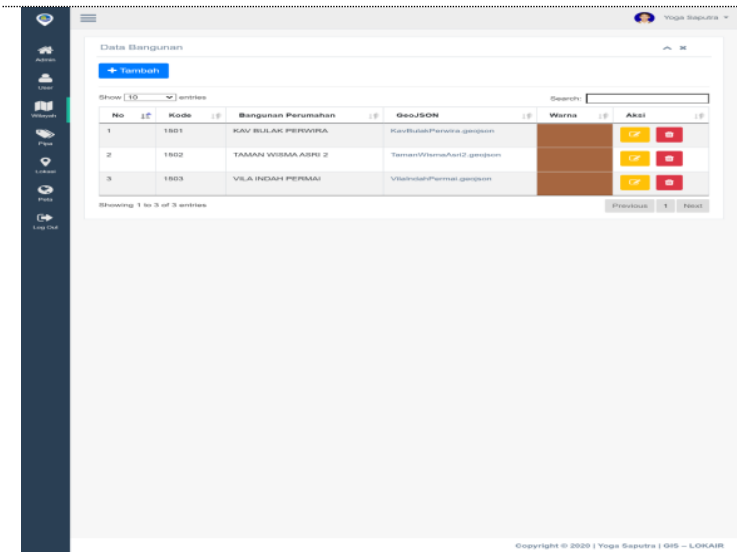

Halaman Bangunan

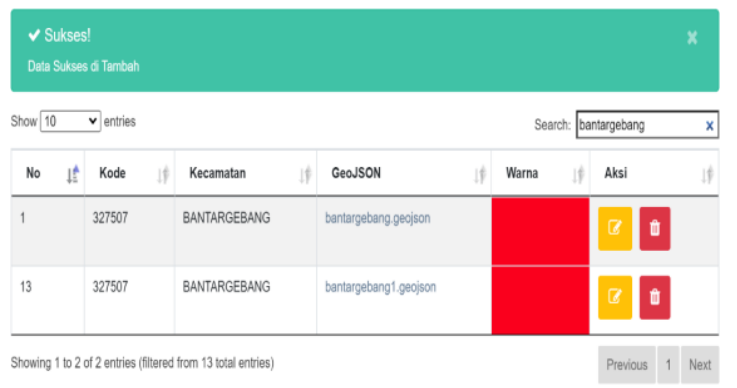

Halaman Kecamatan Info Sukses Tambah

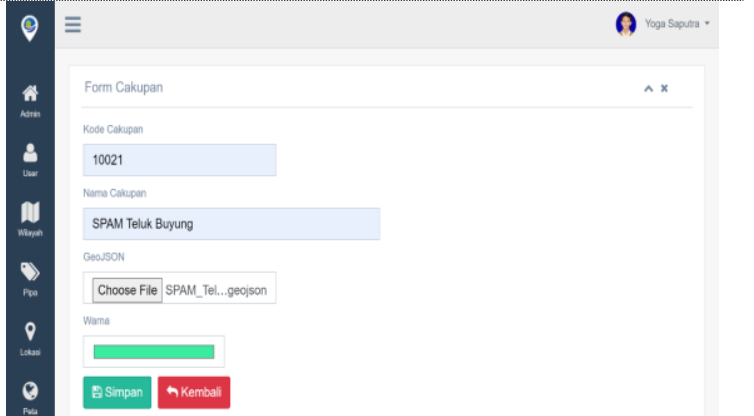

Halaman Tambah dan Ubah Cakupan

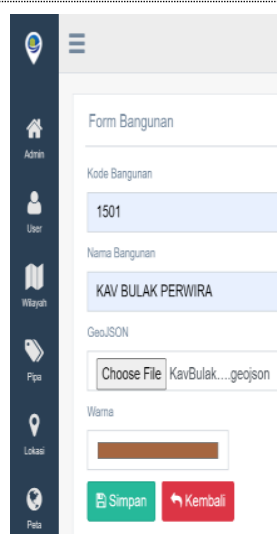

Halaman Tambah dan Ubah Bangunan 


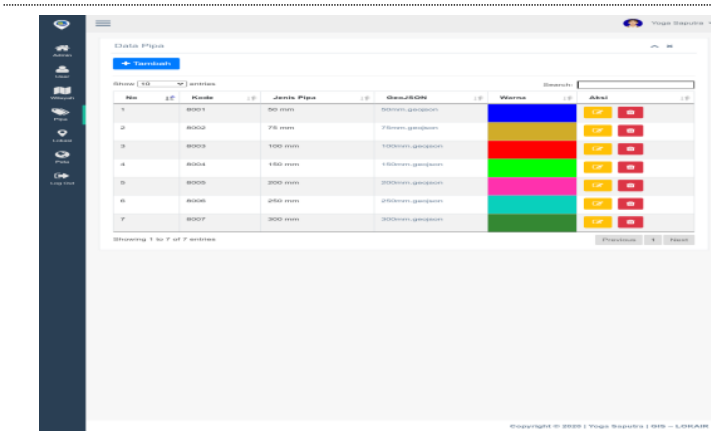

Halaman Pipa

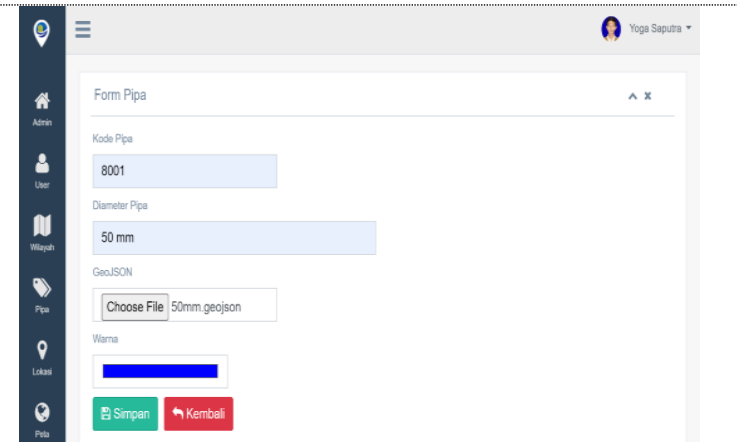

Halaman Tambah \& Ubah Pipa
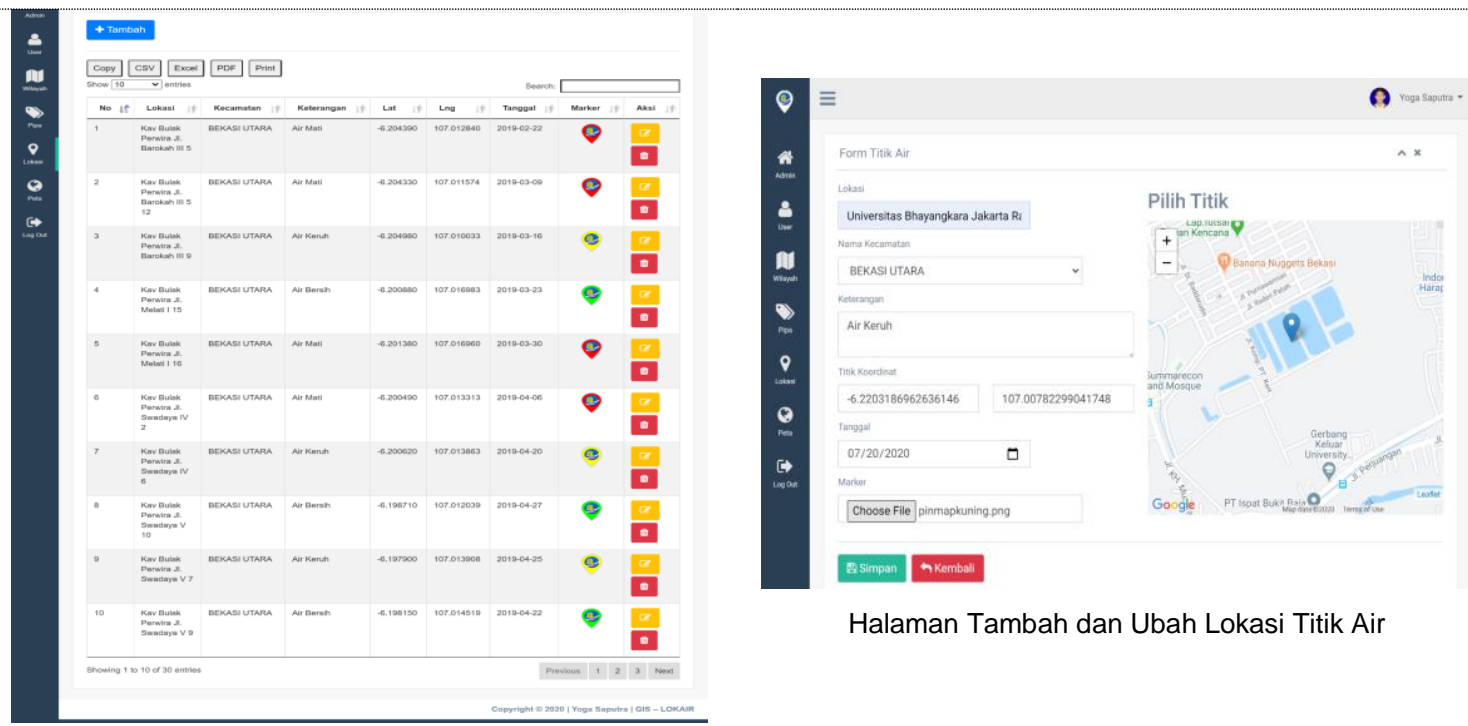

Halaman Tambah dan Ubah Lokasi Titik Air

Halaman Lokasi Titik Air

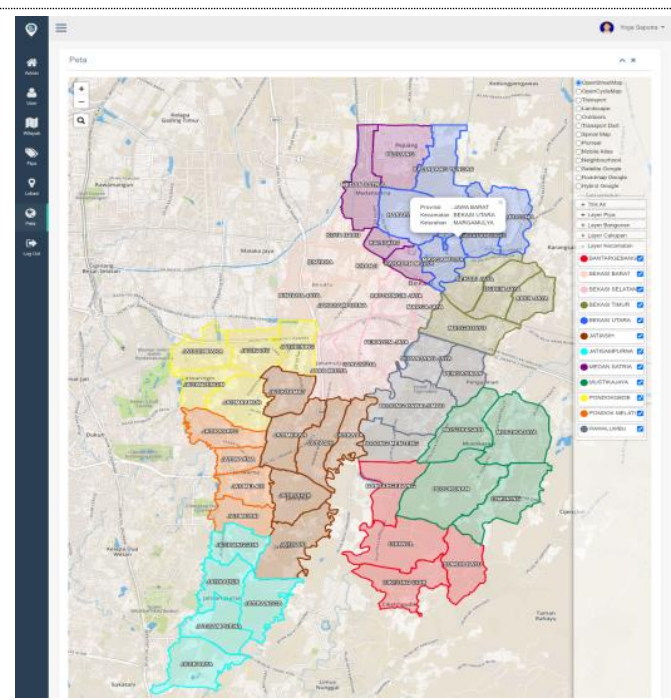

Halaman Peta Layer Kecamatan

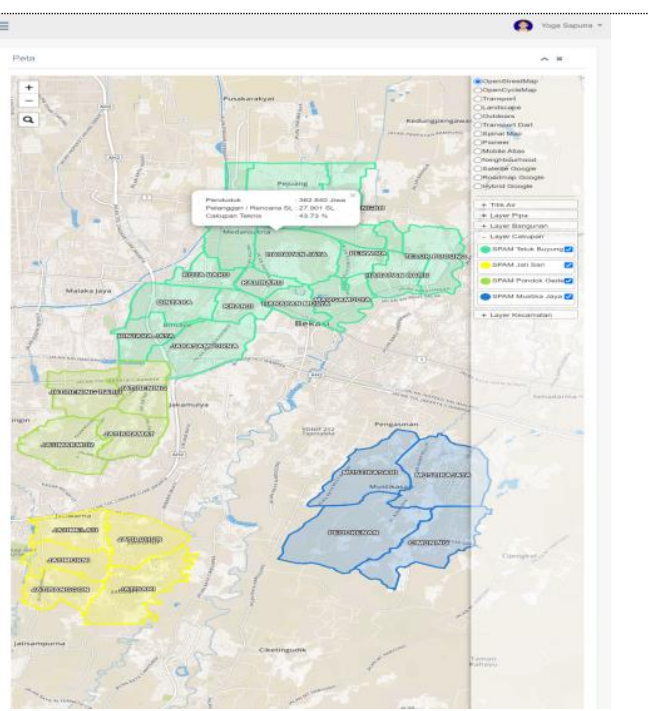

Halaman Peta Layer Cakupan 


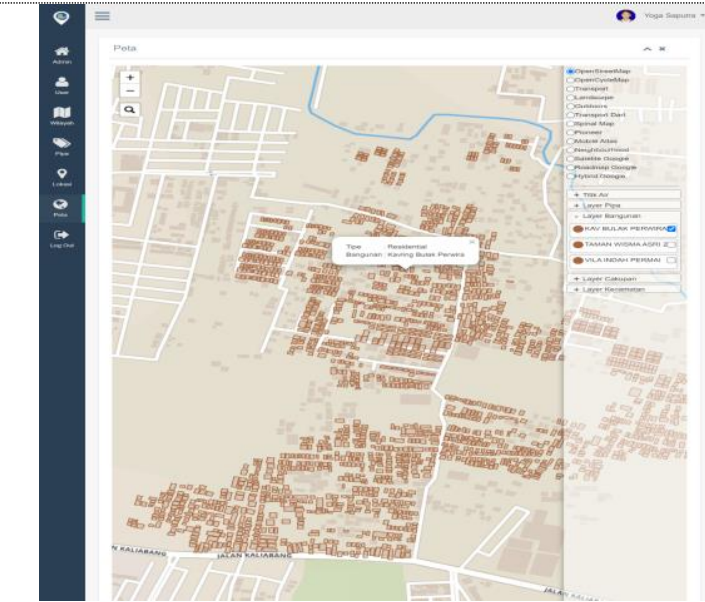

Halaman Peta Layer Bangunan Kavling Bulak

Perwira

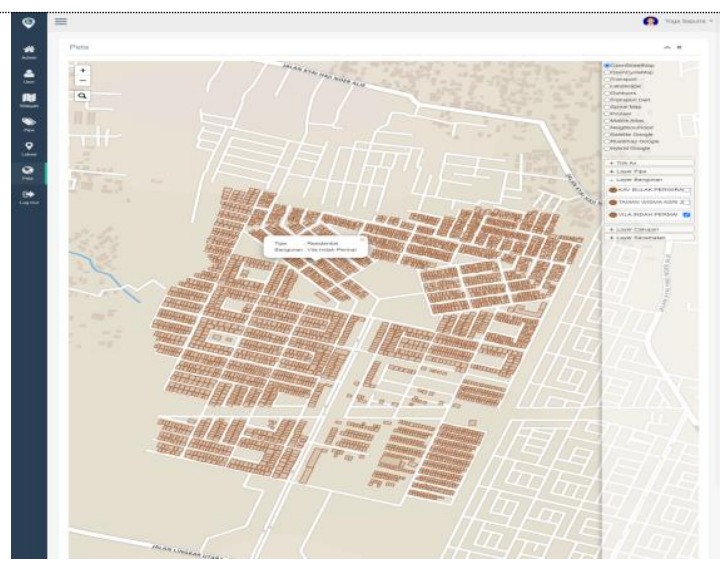

Halaman Peta Layer Bangunan Perumahan

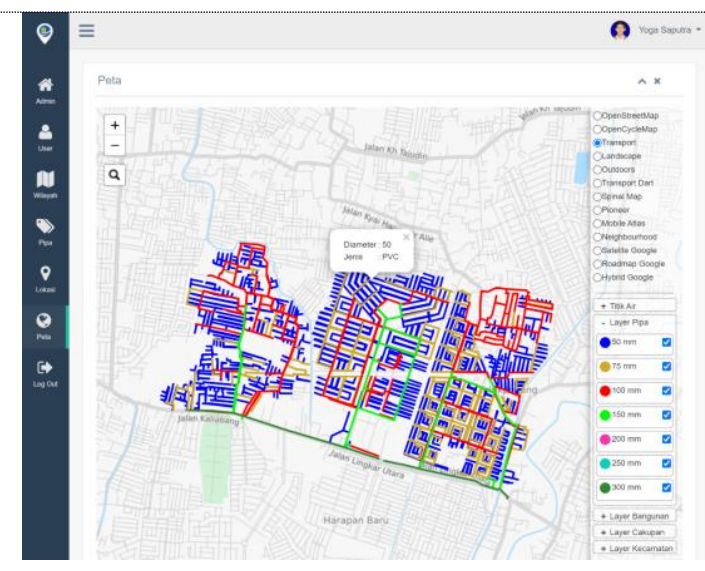

Halaman Peta Layer Pipa Zoom Out

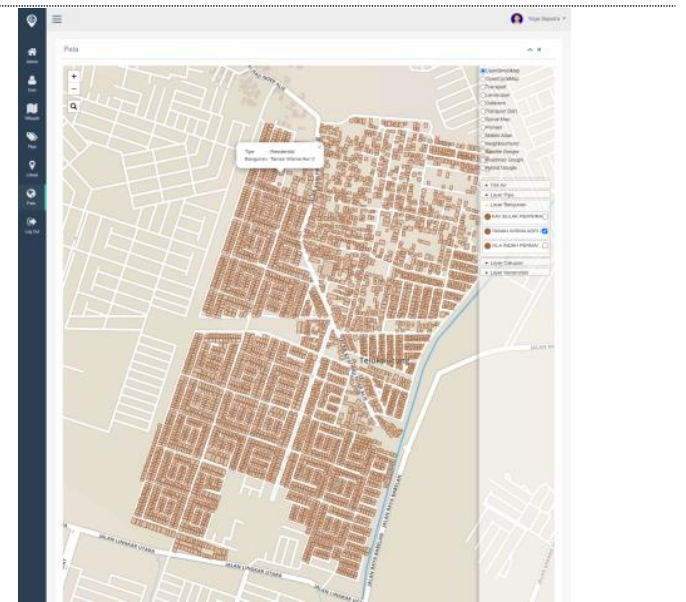

Halaman Peta Layer Bangunan perumahan Taman Wisma Asri 2

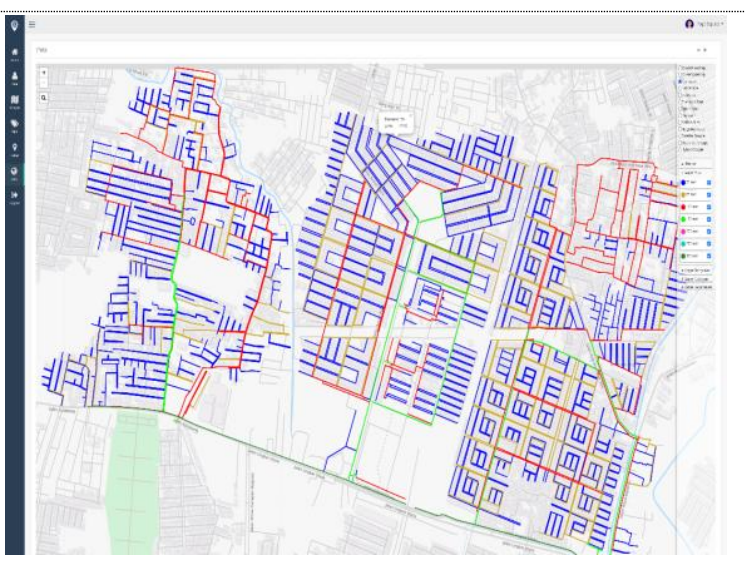

Halaman Peta Layer Pipa Zoom In

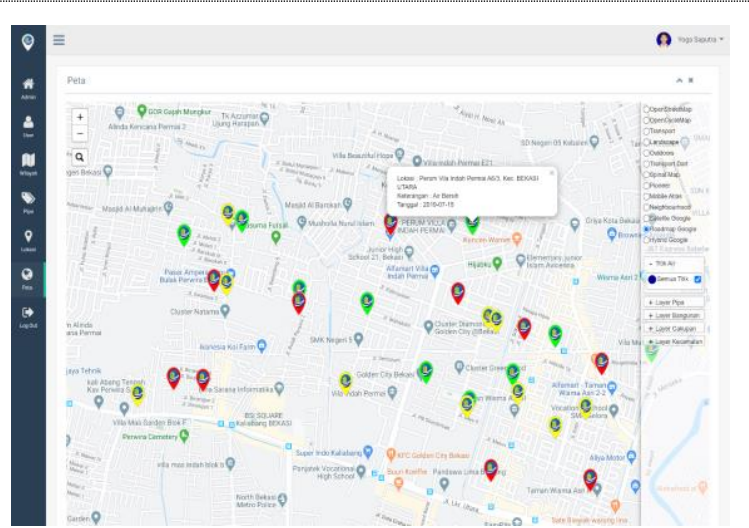

Halaman Peta Layer Lokasi Titik Air 


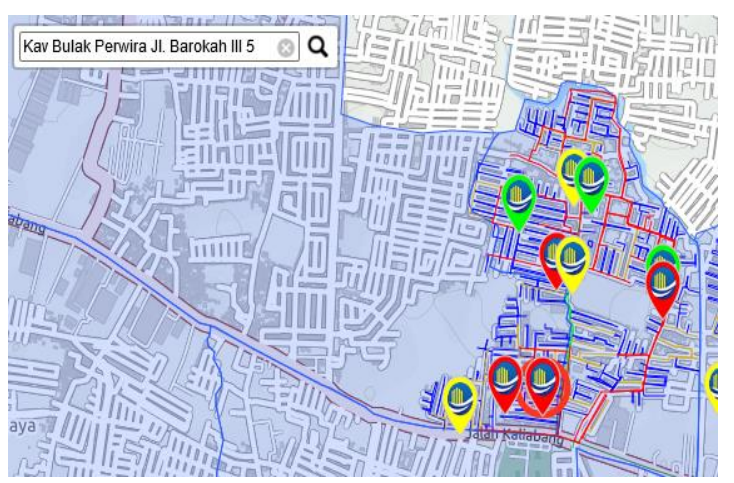

Halaman Peta Pencarian Titik Lokasi

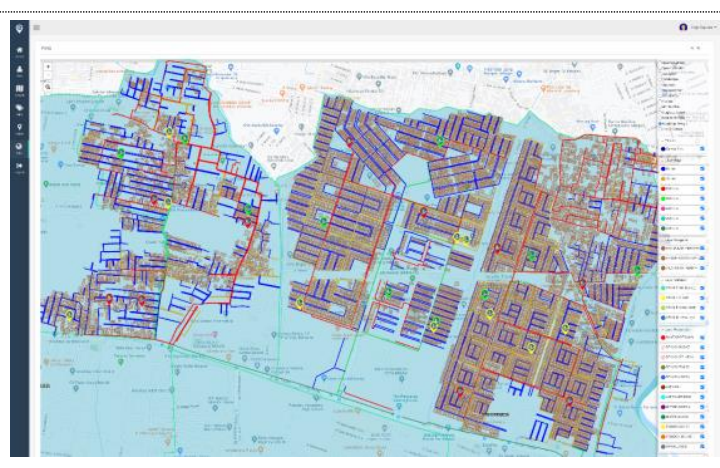

Halaman Peta Layer Aktif Semua Zoom In

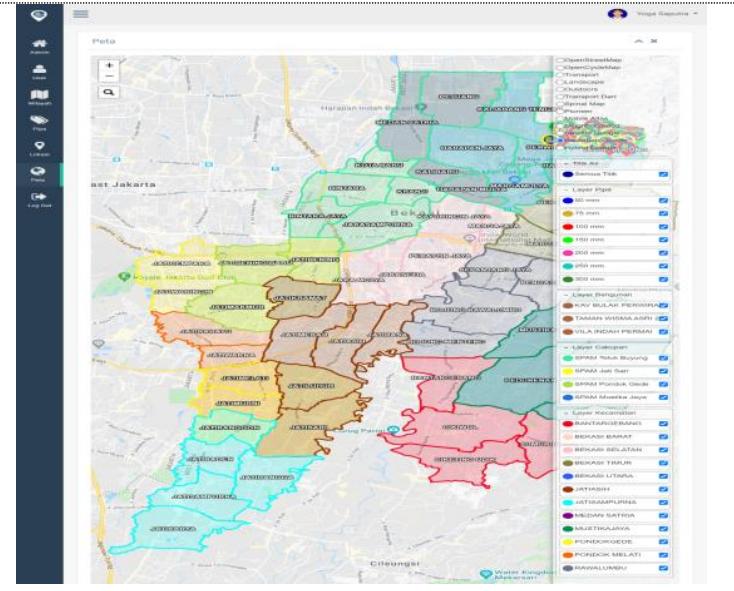

Halaman Peta Layer Aktif Semua Zoom Out

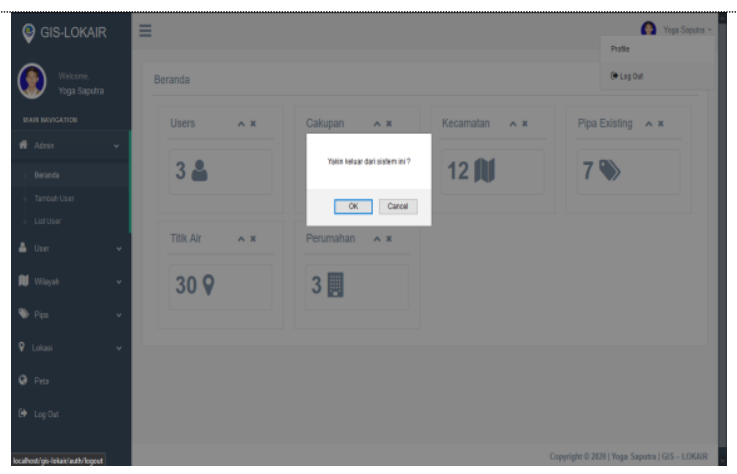

Tampilan Logout

\subsection{Pengujian Black Box}

Pengujian Black Box yaitu menguji fungsi sistem yang ada pada GIS-LOKAIR dan apakah sistem ini memiliki fungsional yang sama saat pengkodean maka disebut sistem tersebut memuat fungsi yang sesuai. Pada pengujian ini ditujukan untuk meminimalisir kesalahan, seperti yang diperlihatkan pada tabel 4 menunjukkan hasil pengujian pada uji data pemetaan.

Tabel 4. Hasil Uji Data Pemetaan

\begin{tabular}{lcc}
\hline Sample Data Access & Result Access & Conclusion Access \\
\hline Login & TRUE & Success \\
\hline Menampilkan Beranda Admin & TRUE & Success \\
\hline Menambah Data User & TRUE & Success \\
\hline Menghapus Data User & TRUE & Success \\
\hline Menampilkan Profil User & TRUE & Success \\
\hline Mengubah Profil User & TRUE & Success \\
\hline Mengubah Password User & TRUE & Success \\
\hline Pengisian Form Kecamatan & TRUE & Success \\
\hline Mengubah Data Kecamatan & TRUE & Success \\
\hline
\end{tabular}




\begin{tabular}{lcc}
\hline Sample Data Access & Result Access & Conclusion Access \\
\hline Menyimpan Data Kecamatan & TRUE & Success \\
\hline Pengisian Form Cakupan & TRUE & Success \\
\hline Mengubah Data Cakupan & TRUE & Success \\
\hline Menyimpan Data Cakupan & TRUE & Success \\
\hline Pengisian Form Bangunan & TRUE & Success \\
\hline Mengubah Data Bangunan & TRUE & Success \\
\hline Menyimpan Data Bangunan & TRUE & Success \\
\hline Pengisian Form Pipa & TRUE & Success \\
\hline Mengubah Data Pipa & TRUE & Success \\
\hline Menyimpan Data Pipa & TRUE & Success \\
\hline Pengisian Form Titik Air & TRUE & Success \\
\hline Mengubah Data Titik Air & TRUE & Success \\
\hline Menyimpan Data Titik Air & TRUE & Success \\
\hline Menampilkan Peta & TRUE & Success \\
\hline Logout & TRUE & Success \\
\hline
\end{tabular}

\section{Kesimpulan}

Hasil dari penelitian ini, mengenai Sistem Informasi Geografis Lokasi Kualitas Air PDAM Patriot Bekasi, maka dapat penulis simpulkan sebagai berikut: (i) dalam penelitian ini dapat mengelola data GIS yang dapat menghasilkan informasi seperti menampilkan lokasi titik air yang memiliki kategori merah jika air mati, kuning jika air keruh, dan hijau jika air bersih, 12 wilayah kecamatan Bekasi, 4 wilayah cakupan layanan, 3 wilayah bangunan perumahan, jaringan pipa pada 3 perumahan dengan pelanggan terbanyak pada PDAM Tirta Patriot Kota Bekasi (ii) adanya GIS-LOKAIR diharapkan membantu masyarakat dalam menginformasikan keluhan air pelanggan berdasarkan data survei kepuasan pelanggan sebagai media informasi juga untuk meningkatkan pelayanan dan operasional kerja PDAM Tirta Patriot Kota Bekasi, dan (iii) GIS-LOKAIR dapat diakses di gis-lokair.com

\section{Ucapan Terima Kasih (Opsional)}

Ucapan terima kasih kami sampaikan kepada Direktur PDAM Patriot Kota Bekasi beserta para jajarannya yang telah bersedia menjadi mitra dalam pelaksanaan penelitian ini.

\section{Daftar Pustaka}

Karimah, M. atul. (2012). Sistem Informasi Geografis Pemetaan Sumber Air dan Reservoir Kabupaten Sleman. Seminar Nasional Informatika Medis III. https://journal.uii.ac.id/snimed/article/view/4090/3644

Maudi, M., Nugraha, A., \& Sasmito, B. (2014). Desain Aplikasi Sistem Informasi Pelanggan 
PDAM Berbasis WEBGIS (Studi Kasus: Kota Demak). Jurnal Geodesi Undip, 3(3), 98110. https://ejournal3.undip.ac.id/index.php/geodesi/article/view/5840

Modul Pelayanan Pelanggan. (2018). Peningkatan Sumber Daya Manusia (SDM) Bidang Air Minum Melalui Program Center Of Excellence (COE).

https://openjicareport.jica.go.jp/pdf/12322467.pdf

Nugroho, B. (2019). Aplikasi Pemrograman Web Dinamis dengan PHP dan MYSQL. Yogyakarta: Gava Media.

Nurrohmah, E., \& Sulistioningrum, D. (2019). Openstreetmap Sebagai Alternatif Teknologi dan Sumber Data Pemetaan Desa Inovasi Untuk Percepatan Pemetaan Desa. Seminar Nasional Geomatika, $\quad 3, \quad 787-796$. http://semnas.big.go.id/index.php/SN/article/viewFile/1067/260

Peraturan Menteri Kesehatan No. 492, (2010) (testimony of Persyaratan Kualitas Air Minum). http://www.ampl.or.id/digilib/read/24-peraturan-menteri-kesehatan-republik-indonesia-no492-menkes-per-iv-2010/50471

Riza, U. (2018). Pengaruh Lokasi, Kelengkapan Produk, dan Harga Terhadap Keputusan Pembelian Di Favorit Swalayan Kamulan. http://repo.iain-tulungagung.ac.id/9662/

Rossa, A. S., \& Shalahuddin, M. (2018). Rekayasa Perangkat Lunak Terstruktur dan Berorientasi Objek (Revisi). Bandung : Informatika.

Susila, A. A. N. H., Piarsa, I. N., \& Buana, P. W. (2016). Sistem Informasi Geografis Pemetaan Jaringan Pipa PDAM Tirta Mangutama. Jurnal Ilmiah Merpati (Menara Penelitian Akademika Teknologi Informasi), 2(2), 262-270. https://ojs.unud.ac.id/index.php/merpati/article/view/17894

USAID IUWASH PLUS. (2015). Fasilitator SIG Untuk Pembangunan Data Spasial PDAM Tirta Patriot Kota Bekasi (pp. 1-63). 